https://helda.helsinki.fi

\title{
The mating system affects the temperature sensitivity of male and female fertility
}

\section{Baur, Julian}

2022-01

Baur, J , Jagusch , D , Michalak , P , Koppik, M \& Berger , D 2022 , ' The mating system affects the temperature sensitivity of male and female fertility ', Functional Ecology , vol. 36 , no. 1 , pp. 92-106 . https://doi.org/10.1111/1365-2435.13952

http://hdl.handle.net/10138/338448

https://doi.org/10.1111/1365-2435.13952

cc_by

publishedVersion

Downloaded from Helda, University of Helsinki institutional repository.

This is an electronic reprint of the original article.

This reprint may differ from the original in pagination and typographic detail.

Please cite the original version. 


\title{
The mating system affects the temperature sensitivity of male and female fertility
}

\author{
Julian Baur $^{1}$ (D) | Dorian Jagusch ${ }^{1,2}$ | Piotr Michalak $^{1}$ | Mareike Koppik $^{1}$ (D) | \\ David Berger ${ }^{1}$ (C)
}

\author{
${ }^{1}$ Department of Ecology and Genetics, \\ Uppsala University, Uppsala, Sweden \\ ${ }^{2}$ Organismal and Evolutionary Biology \\ Research Program, Faculty of Biological \\ and Environmental Sciences, University of \\ Helsinki, Helsinki, Finland

\section{Correspondence} \\ Julian Baur \\ Email: julian.baur@ebc.uu.se \\ Funding information \\ Carl Tryggers Stiftelse för Vetenskaplig \\ Forskning, Grant/Award Number: 18, CTS \\ and 32; Vetenskapsrådet, Grant/Award \\ Number: 2015-05223 and 2019-05024 \\ Handling Editor: Pau Carazo
}

\begin{abstract}
1. To mitigate the effects of climate change, it is important to understand species' responses to increasing temperatures. This has often been done by studying survival or activity at temperature extremes. Before such extremes are reached, however, effects on fertility may already be apparent.

2. Sex differences in the thermal sensitivity of fertility (TSF) could impact species persistence under climate warming because female fertility is typically more limiting to population growth than male fertility. However, little is known about sex differences in TSF.

3. Here we first demonstrate that the mating system can strongly influence TSF using the seed beetle Callosobruchus maculatus. We exposed populations carrying artificially induced mutations to two generations of short-term experimental evolution under alternative mating systems, manipulating the opportunity for natural and sexual selection on the mutations. We then measured TSF in males and females subjected to juvenile or adult heat stress.

4. Populations kept under natural and sexual selection had higher fitness, but similar TSF, compared to control populations kept under relaxed selection. However, females had higher TSF than males, and strikingly, this sex difference had increased over only two generations in populations evolving under sexual selection.

5. We hypothesized that an increase in male-induced harm to females during mating had played a central role in driving this evolved sex difference, and indeed, remating under conditions limiting male harassment of females reduced both male and female TSF. Moreover, we show that manipulation of mating system parameters in C. maculatus generates intraspecific variation in the sex difference in TSF equal to that found among a diverse set of studies on insects.

6. Our study provides a causal link between the mating system and TSF. Sexual conflict, (re)mating rates and genetic responses to sexual selection differ among ecological settings, mating systems and species. Our study therefore also provides mechanistic understanding for the variability in previously reported TSFs which
\end{abstract}

This is an open access article under the terms of the Creative Commons Attribution License, which permits use, distribution and reproduction in any medium, provided the original work is properly cited.

(c) 2021 The Authors. Functional Ecology published by John Wiley \& Sons Ltd on behalf of British Ecological Society. 
can inform future experimental assays and predictions of species responses to climate warming.

\section{KEYWORDS}

climate change, fecundity, fertility, heat shock, sexual conflict, sexual selection, sperm, thermal fertility limits

\section{INTRODUCTION}

To predict evolutionary trajectories of natural populations experiencing warming climates, it is necessary to understand selection on, and the genetic architecture of, traits whose expression depends heavily on temperature (Bubliy et al., 2012; Chevin et al., 2013; Hoffmann \& Sgrò, 2011; Walters et al., 2012). Typical estimates of thermal sensitivity describe the temperatures at which individuals fail to maintain basic physiological functions such as controlled locomotion and respiration (Lutterschmidt \& Hutchison, 1997). Approaches to predict organismal responses relying exclusively on such measures are however bound to neglect a variety of sublethal effects that will arise at less extreme temperatures, the most important being reductions in fertility (Angilletta, 2009; Chirgwin et al., 2021; Hoffmann et al., 2013; Kellermann \& van Heerwaarden, 2019; Parratt et al., 2021; Walsh et al., 2019). Indeed, already a slight decrease in fertility can have dramatic effects on population viability (Degioanni et al., 2019) and thermal plasticity in reproductive traits affecting fertility is widespread (Dell et al., 2011; Deutsch et al., 2008; Frazier et al., 2006) and often observable at a significantly lower temperature threshold than responses in viability (Angilletta, 2009; Gerking \& Lee, 1983; Hoffmann, 2010; Loisel et al., 2019; van Heerwaarden \& Sgrò, 2021). Hence, it is crucial to incorporate estimates of the thermal sensitivity of fertility (from hereon: TSF) into predictions of population persistence (Angilletta, 2009; Parratt et al., 2021; Walsh et al., 2019).

In many sexually reproducing species, population growth is mainly dependent on female fertility (Caswell, 2006). Female TSF may therefore be more consequential for population viability under climate warming than male TSF, highlighting the need for a more thorough understanding of sex differences in TSF (Iossa, 2019). For example, if male fertility is more sensitive to elevated temperatures so that selection for thermal tolerance acts more strongly in males, and assuming some shared genetic basis for TSF in the two sexes, then genetic variation with deleterious effects on female TSF could effectively be purged via males. This in turn could limit the cost of adaptation (sensu Haldane, 1957) at high temperature mainly to males. Such male-biased purging of deleterious alleles affecting TSF could thus pursue with little reduction in population growth, which would aid evolutionary rescue of sexually reproducing species facing warming climates (Godwin et al., 2020; Manning, 1984; MartinossiAllibert, Rueffler, et al., 2019; Martinossi-Allibert, Thilliez, et al., 2019; Plesnar-Bielak et al., 2012; Whitlock \& Agrawal, 2009). It has been suggested that male reproduction is more affected by elevated temperature in both endotherms (Hansen, 2009) and ectotherms (David et al., 2005; Jørgensen et al., 2006). However, male and female reproductive physiologies are vastly different (García-Roa et al., 2020; Kodric-Brown \& Brown, 1987), questioning whether genetic responses to selection on TSF in one sex would be consequential for TSF in the other. On the other hand, some general buffering mechanisms against elevated temperature, such as antioxidant defences (Dowling \& Simmons, 2009) or molecular chaperones aiding protein translation and folding (Feder et al., 2000), are costly to produce and may depend strongly on the overall condition and genetic quality of the individual. Such responses may therefore be much more likely to share a genetic basis between the sexes (Andersson, 1994; Rowe \& Houle, 1996; Tomkins et al., 2004).

Sex differences are often rooted in the operation of sexual selection and mating systems, and it is possible that sex specificity in TSF could trace back to general differences in male and female reproductive physiologies ingrained in the evolution of anisogamy (Schärer et al., 2012). However, fine-grained variation in sexual selection and mating systems is also likely to play an important role in shaping male and female TSF (García-Roa et al., 2020; Gómez-Llano et al., 2020; Martinossi-Allibert, Rueffler, et al., 2019; Martinossi-Allibert, Thilliez, et al., 2019; Pilakouta \& Ålund, 2021; Svensson et al., 2020). For example, success under post-copulatory sexual selection (i.e. sperm competition) can depend on both gamete quality (Gage et al., 2004; Hosken et al., 2003; McNamara et al., 2014) and the overall genetic quality of the male (Hosken et al., 2003), suggesting that sexual selection for genetic quality could increase tolerance to thermal stress. However, sperms' tolerance of oxidative stress, and therefore likely also of high temperature, can be affected by investment in precopulatory traits (Dowling \& Simmons, 2009; Helfenstein et al., 2010) and studies have suggested that male gamete quality may trade-off with investment into reproductive competition (Baur \& Berger, 2020; Silva et al., 2019). Female reproduction is also sensitive to temperature, especially because egg maturation and oviposition are two highly temperaturedependent processes (Angilletta, 2009; Berger et al., 2008; Kingsolver \& Huey, 2008; Schou et al., 2021), and it is likely that female TSF could be modulated further by pre- and post-fertilization mating interactions. For example, physical harm inflicted via male harassment of females during copulation, or physiological harm mediated via toxic ejaculate compounds (Arnqvist \& Rowe, 2005; Dougherty et al., 2017; Parker, 2006), could increase female TSF if TSF is dependent on the condition of the individual and costly thermal buffering mechanisms. 
On the other hand, some ejaculate compounds typically have beneficial effects in females (Arnqvist \& Nilsson, 2000; Karlsson et al., 1997; Oku et al., 2019; Parrett \& Knell, 2018; Reinhardt et al., 2009; Savalli $\&$ Fox, 1999), and remating could potentially improve male fertility via gamete renewal. This suggests that sex differences in TSF are bound to vary dynamically with mating system parameters.

Here we explore the role of the mating system in shaping sex differences in TSF in populations of the polyandrous seed beetle Callosobruchus maculatus. We first quantified how two generations of natural and sexual selection on artificially induced mutations affected short-term evolutionary responses in male and female TSF. This approach was motivated by (a) theory often assuming that sexual selection is a more potent force of purifying selection against deleterious genetic variation compared to natural selection (Rowe $\&$ Houle, 1996; Tomkins et al., 2004; Whitlock \& Agrawal, 2009) and that purging of deleterious genetic variation is much more efficient via sexual selection in males in C. maculatus (Grieshop et al., 2016, 2021), (b) the notion that compensatory physiological responses to temperature stress are costly (Feder et al., 2000), suggesting that TSF may be dependent on the condition and overall genetic quality of the individual, and (c) the observation that elevated temperature can increase the effects of deleterious genetic variation in ectotherms (Berger et al., 2021).

To this end, we induced an appreciable genetic load via mutagenesis in replicate populations that were subsequently propagated for two generations under three alternative experimental evolution regimes: polygamy (imposing natural and sexual selection), enforced monogamy (natural selection only) and relaxed selection (natura and sexual selection removed). Comparisons to the ancestral (nonirradiated) populations allowed us to assess the relative impact of the induced mutations and the extent to which the two mating systems (polygamy and monogamy) had purged the mutations relative to the relaxed selection treatment. Thus, in addition to providing information on sex differences in TSF in C. maculatus, this panel of populations allowed us to assess not only sex-specific effects of de novo mutations on TSF but also how natural and sexual selection on de novo mutations influence sex differences in TSF.

We conducted the experiment using two different types of heat stress. We applied a short-term but high intensity heat shock on adult beetles, reflecting extreme daily maximal temperatures, which are predicted to increase in frequency due to climate change (Johnson et al., 2018). In a parallel experiment using the same populations, we applied long-term heat stress throughout the entire larval development, as may result from increasing variation in average monthly temperatures (Bathiany et al., 2018; Varela et al., 2020).

\section{2 | MATERIALS AND METHODS}

\section{1 | Study population}

Callosobruchus maculatus is a common pest on fabaceous seeds in tropical and subtropical regions. Females cement eggs onto host seeds and the larvae burrow into the seed where they complete their development within 3 weeks under standard laboratory conditions $\left(29^{\circ} \mathrm{C}, 12 \mathrm{~L}: 12 \mathrm{D}\right.$ light cycle, $55 \%$ rel. humidity), on their preferred host, Vigna unguiculata (Fox, 1993). Unless otherwise stated, the standard laboratory conditions, outlined above, were used for population maintenance in all the experiments described below. Egg-to-adult survival is above $90 \%$ in the populations used here (J. Baur, pers. obs.). Adults are facultatively aphageous and start reproducing within hours after emergence. Under laboratory conditions without food or water adult beetles live just over 1 week with most of the reproduction taking place within the first few days (Fox, 1993). Callosobruchus maculatus has a polyandrous mating system with documented sexual conflict over (re)mating and high remating rates, leading to both preand post-copulatory sexual selection on males (Berger et al., 2016; Crudgington \& Siva-Jothy, 2000; Eady, 1995; Gay et al., 2009; Hotzy \& Arnqvist, 2009). Once a male manages to successfully initiate copulation, spines on its genitalia help to prevent it from being dislodged but at the same time harm the female (Bagchi et al., 2021; Edvardsson \& Tregenza, 2005; Rönn \& Hotzy, 2012; Rönn et al., 2007). The effects of the genital spines and the harm imposed on the females have been found to correlate with a male's sperm competitiveness (Hotzy \& Arnqvist, 2009) and, in a congener that exhibits similar genital structures, also increase female oviposition rate as a response to genital scarring (Haren et al., 2017). Female reproductive behaviour is further modulated by lifespan-extending nutrients and water (Rönn et al., 2006) and likely also other functional compounds in the male ejaculate (Bayram et al., 2019), suggesting that the male ejaculate can have both positive and negative effects on female fertility (Arnqvist et al., 2004; Yamane et al., 2015).

The stock used for the experimental populations originates from 41 iso-female lines sampled in Lomé, Togo $\left(06^{\circ} 10 \# \mathrm{~N} 01^{\circ} 13 \# \mathrm{E}\right.$; see Berger et al., 2014) that were mixed and maintained at large population size $(N>300)$ for roughly 50 generations under standard conditions prior to the start of this experiment.

\section{2 | Mutagenesis}

The stock population was split into three replicate founder populations (Figure 1a), each one serving as the starting population for an experimental block containing all four types of populations (a control and the three experimental evolution regimes). The blocks were separated by 3 days. We first introduced a genetic load in the three founders by exposing male beetles to $25 \mathrm{~Gy}$ of $\gamma$-radiation over $32 \mathrm{~min}$ (dose rate: $\sim 0.79 \mathrm{~Gy} / \mathrm{min}$ ). This dose is known to reduce fertility (i.e. number of emerging adults) of the parental generation by roughly $70 \%$ and that of the F1 generation by roughly $40 \%$ (Baur \& Berger, 2020; Grieshop et al., 2016). All irradiated males ( $N=150$ per founder) were virgin and eclosed between 0 and $24 \mathrm{hr}$ prior to irradiation. All males were then mated to a randomly assigned female (enforced monogamy). Matings were carried out in empty $60 \mathrm{~mm}$ petri dishes on a heating plate and observed by an experimenter to ensure a successful mating. Subsequently, the females were transferred to a 2-litre jar 


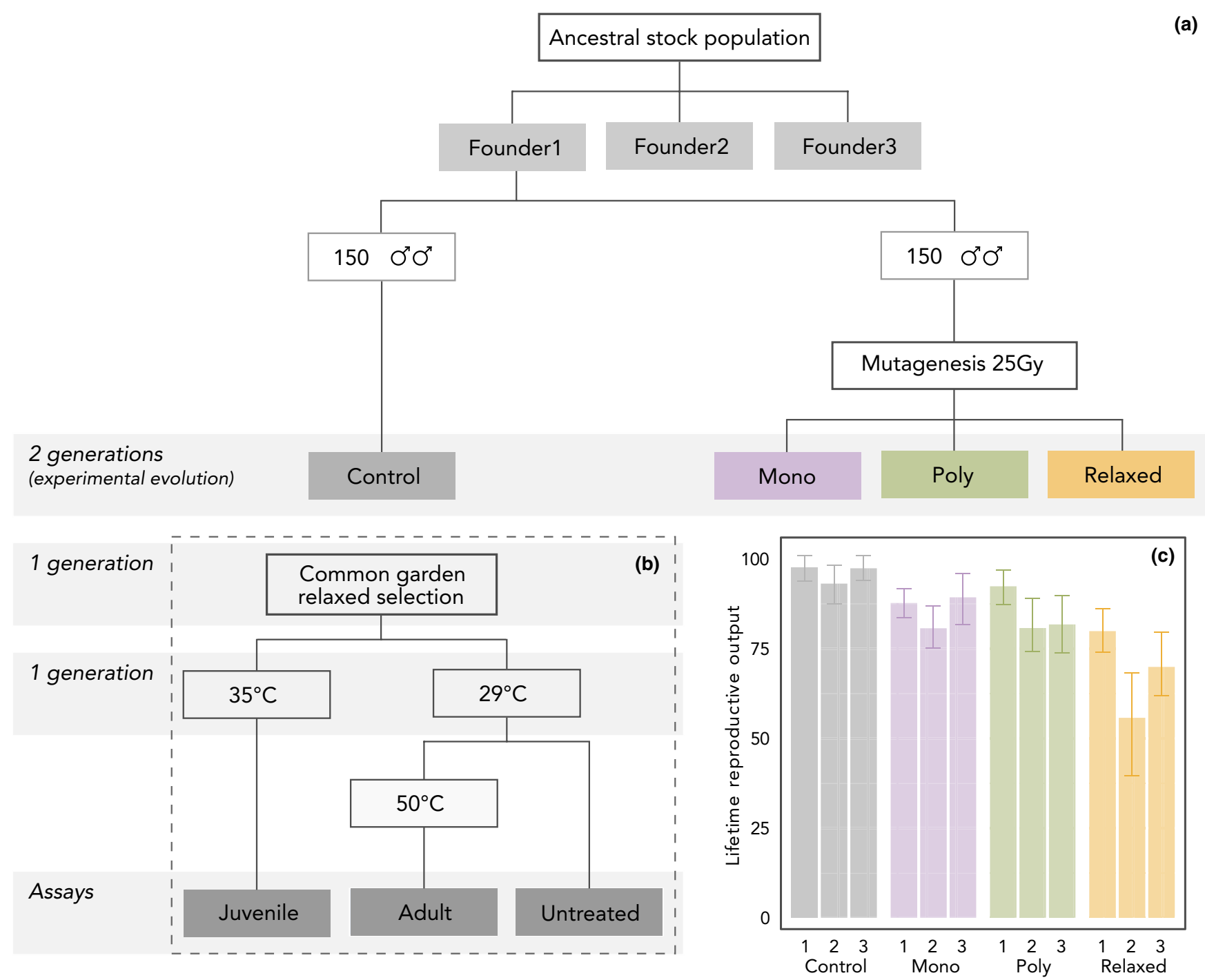

FIGURE 1 Experimental design used to obtain the two main data sets. (a) Founding populations, mutagenesis and experimental evolution. (b) Juvenile heat stress (development at $35^{\circ} \mathrm{C}$ ) and adult heat shock $\left(20\right.$ min heat shock at $50^{\circ} \mathrm{C}$ ) applied to all 12 populations. (c) Lifetime reproductive output of all 12 populations in the benign environment (untreated). Shown are means $\pm 95 \%$ confidence intervals

containing host seeds ad libitum and allowed to lay eggs for $48 \mathrm{hr}$. Egg-laden beans were mixed and distributed into three aliquots marking the starting point for the three experimental evolution regimes (see below). At this point, all offspring are expected to carry a random set of mutations induced via their fathers. Another 150 control (nonirradiated) males were used to seed the control population for each founder. These control populations were propagated according to the same mating regime as the polygamy populations outlined below.

\section{3 | Experimental evolution regimes}

The selection regime protocols (Figure 1a), outlined below, have previously been described and used in several, more long-term (up to 60 generations), experimental evolution studies in C. maculatus and have been shown to result in pronounced sex-specific adaptations (Bagchi et al., 2021; Baur et al., 2019; Baur \& Berger, 2020; Martinossi-Allibert,
Rueffler, et al., 2019; Martinossi-Allibert, Thilliez, et al., 2019). To minimize larval competition, all regimes were provided beans ad libitum $(\sim 4,800$ beans) and females of all regimes were removed from the beans after $48 \mathrm{hr}$ of egg-laying. The relatively large population size (Polygamy: $N_{e} \leq 100$, Monogamy: $N_{e} \leq 120$, Relaxed: $N_{e} \leq 200$ ) and short time of the experimental evolution experiment should preclude effects of genetic drift affecting the results. Note that we here applied the following selection regimes over two generations to a population carrying an artificially induced genetic load. The achieved effects must not necessarily reflect the effects of a long-term experimental evolution study using standing genetic variation.

\subsection{1 | Polygamy}

This regime resembles the natural mating system, including sexual and natural selection on males and females. In all, 100 virgin 
males and 100 virgin females were picked within $72 \mathrm{hr}$ after eclosion and collected in a 1-litre jar with beans. The beetles could freely interact, compete, mate and lay eggs for $48 \mathrm{hr}$. This mating scheme was also used to propagate the non-irradiated control populations.

\subsection{2 | Monogamy}

This regime removes sexual selection but applies natural (fecundity) selection on females and males. Within $72 \mathrm{hr}$ after eclosion, 100 virgins of each sex were picked and randomly paired and allowed to mate for $5 \mathrm{hr}$ in an empty $60 \mathrm{~mm}$ petri dish. During this period, the male and female could freely interact and mate repeatedly. After $5 \mathrm{hr}$, the males were removed, and all females were collected and placed together in a 1-litre jar containing host seeds.

\subsection{3 | Relaxed selection}

This regime removes both natural and sexual selection to retain the induced (non-lethal) deleterious mutations in the populations. Within $72 \mathrm{hr}$ after eclosion, 100 virgin females and 100 virgin males were assigned to form random monogamous couples (avoiding inbreeding) as in the monogamous mating regime. However, under this regime each couple was only allowed a single mating (in contrast to the 5-hr mating period under the monogamous regime). Thereafter, males were removed, and each female was provided with beans. In the next generation, offspring were picked so that each parental couple contributed exactly one female and one male to the next generation.

We applied experimental evolution for only two generations on artificially induced deleterious mutations. Previous studies (Baur \& Berger, 2020; Grieshop et al., 2016) have shown that induced mutations are quickly removed continuously with each additional generation in the laboratory and we therefore assayed fertility of the populations following this short protocol, expecting this to result in the greatest chance to detect effects of the selection regimes on mutation load. Thus, after two generations of propagation under the selection regimes, we applied one generation of common garden relaxed selection (Figure $1 \mathrm{~b}$ ) to all 12 populations to both counteract potential influence of parental effects and to prevent further selection against deleterious mutations (Figure 1a). We then established 30 mating couples, later referred to as families, per population (total $n_{\text {family }}=360$ ). We kept track of these initial families throughout the experiment to avoid inbreeding during subsequent crosses. After mating, we allowed the female to lay eggs for $48 \mathrm{hr}$. We then removed the female and evenly split the beans from each female into one half that was subjected to the Juvenile heat stress treatment (outlined below), and one half that was kept developing at benign $29^{\circ} \mathrm{C}$ (Figure 1b). The beetles developing at $29^{\circ} \mathrm{C}$ were assigned to undergo the Adult heat shock treatment (outlined below) or to remain untreated and serve as control for both heat treatments
(Figure 1a,b). Note that we measure thermal sensitivity of fertility (TSF) under both heat treatments and not the commonly used thermal fertility limit (TFL). The main distinction being that the TFL describes the critical temperature at which all reproduction ceases, while TSF is used to describe any reduction of fertility due to stressful temperatures.

\section{Juvenile heat stress}

1.1. This experiment was designed to resemble a longer period of elevated temperature as, for example, a heat wave, which can occur in the months of March and April in Lomé, Togo. Current projections for Lomé predict an increase of the average daily maximal temperature in the months from February to April from $32^{\circ} \mathrm{C}$ in the late 20th century, up to a maximum of $37.2^{\circ} \mathrm{C}$ by the end of the 21 st century (Varela et al., 2020). Beetles assigned to this treatment developed at an elevated temperature of $35^{\circ} \mathrm{C}$ throughout their entire larval and pupal stage (ca. 21 days in total). To estimate the sex-specific fertility loss due to development at $35^{\circ} \mathrm{C}$ for each of the 12 populations, we crossed an individual from one family with an opposite-sex individual from another family (but same population), while varying the treatment from which the individuals were picked. This resulted in a total of 818 untreated couples, 458 couples with a treated female and 443 couples with a treated male. Each couple was provided with beans ad-libitum in a $60 \mathrm{~mm}$ petri dish and allowed to mate and lay eggs for the rest of their lives. This type of assay gives an estimate of lifetime reproductive output under cohabitation, allowing for all sorts of male-female interactions including remating and male harassment. Emerging adult offspring were later counted to obtain the fertility of the couple.

1.2. Remating and male harassment: To understand the mechanisms behind the results of experiment 1.1, we explored putative effects of multiple mating via male ejaculatory compounds and harmful physical interactions on female TSF. Using beetles from the stock population, we exposed 24-hr-old virgin heat-treated (developed at $35^{\circ} \mathrm{C}$ ) and untreated (developed at $29^{\circ} \mathrm{C}$ ) females to three male treatments (all males developed at $29^{\circ} \mathrm{C}$ ). Females in the first treatment underwent a single observed mating, after which we removed the male and allowed the female to deposit eggs for the rest of her lifetime. Females undergoing the second treatment were mated once per day to the same male for three consecutive days with the male being removed between matings (multiple mating without harassment). In the third treatment, we co-reared the male and female for their entire life, allowing them to interact freely as was the case in the original experiment (multiple mating with harassment).

1.3. Interaction of male and female heat stress: We tested whether the effects of female and male juvenile heat stress act in an additive manner on a couple's fertility. We reared male and female beetles from the stock population at a benign $\left(29^{\circ} \mathrm{C}\right)$ or a stressful $\left(35^{\circ} \mathrm{C}\right)$ temperature. Within $24 \mathrm{hr}$ after emergence, we paired a male and female beetle of which the male, the female, both sexes, or none of the sexes had developed at elevated temperature. Males and females were co-reared for their entire life, and we counted the couple's reproductive output. 


\section{Adult heat shock}

2.1. This experiment was designed to simulate a short-term heat extreme as occurring in the form of extreme daily maxima. We chose an exposure intensity of $50^{\circ} \mathrm{C}$ for $20 \mathrm{~min}$ because a pilot experiment showed that ca. $50 \%$ of the beetles were knocked-out in the process (no more perceptible movement), but at the same time it remains ecologically relevant as such temperatures are likely to be reached in sun-exposed microclimates within the range of this species (Deutscher Wetterdienst, n.d.). From the beetles that developed at benign $29^{\circ} \mathrm{C}$, we randomly picked three adult female and three adult male beetles per family. We put beetles singly in a perforated $0.5 \mathrm{ml}$ Eppendorf tube, all beetles were then placed together in a closed $200 \mathrm{~mm}$ petri dish on a heating plate set to $50^{\circ} \mathrm{C}$. The air temperature inside the upper part of the petri dish was also monitored and remained constant at $43^{\circ} \mathrm{C}$ for the duration of the treatment. We paired all heat-exposed beetles with an untreated individual of opposite sex from a different family, but from the same population, resulting in 818 untreated couples, 500 couples with a treated female and 540 couples with a treated male. Each couple was provided with ad-libitum beans in a $60 \mathrm{~mm}$ petri dish and lifetime reproductive output was recorded.

2.2. Male recovery: Using the stock population, we investigated whether recovery of the male after heat shock may have shaped the observed sex differences in TSF in the main experiment (2.1) outlined above. We allowed one group of males to mate $2 \mathrm{hr}$ after the heat shock treatment. Beetles of this group were then allowed to mate again $26 \mathrm{hr}$ after heat shock. The second group of male beetles were only allowed to mate once, after $26 \mathrm{hr}$. Beetles assigned to the untreated control group were subdivided into the same two groups to control for a possible decline in fertility due to repeated mating, although this has been shown to be minimal in C. maculatus (Rönn et al., 2008). This allowed us to independently estimate effects of recovery over time and recovery through mating, causing ejaculate replacement, on male TSF.

\subsection{Statistical analysis}

All analyses were executed in R (R Core Team, 2020). We fitted generalized linear mixed models assuming a Poisson distributed response using the package LME4 (Bates et al., 2015, p. 4). We used generalized linear models to analyse those follow-up experiments that lack random terms. The R package GGPLOT2 (Wickham, 2016) was used for graphical illustration. P-values were calculated using the package CAR (Fox \& Weisberg, 2019) using type-II sums of squares. Planned post-hoc comparisons, applying Tukey correction, were conducted using the package EMMEANs (Lenth, 2020).

1.1 \& 2.1 Sex-specific TSF in evolution regimes: Offspring number was used as the response while evolution regime and treatment (male stress, female stress or untreated), as well as their interaction, were added as fixed effects. We added experimental block and the identity of the experimenter counting offspring as additional terms. Population replicate crossed with treatment, as well as dam and sire effects, were included as random effects. Additionally, an observation level random effect (OLRE) was included to control for over-dispersion.

1.2. Remating and male harassment: We analysed main effects of female development treatment $\left(29 / 35^{\circ} \mathrm{C}\right.$ ), mating (single/multiple) and cohabitation (isolated/cohabiting), as well as two-way interactions between development treatment and mating or cohabitation. Experimental date was added as an additional main effect. We assumed Poisson-distributed errors while correcting for overdispersion via the quasi-extension in both models.

1.3. Interaction of male and female heat stress: We analysed effects of female development treatment $\left(29 / 35^{\circ} \mathrm{C}\right)$, male development treatment $\left(29 / 35^{\circ} \mathrm{C}\right)$ and their interaction as fixed factors assuming Poisson-distributed errors.

2.2 Male recovery: To test for the effect of remating on male TSF to heat shock, we ran a generalized linear mixed model with a Poisson response including treatment (untreated, heat shocked), mating number (one ( $2 \mathrm{hr}$ ) or two $(26 \mathrm{hr})$ ) and their interaction as fixed effects, and male identity, as well as an OLRE, as random effects. When analysing the effect of recovery time without mating, male identity and the interaction term were dropped because males only mated once.

\section{3 | RESULTS}

There were pronounced fertility differences between irradiated and control populations when assayed only in the benign environment (i.e. untreated beetles), illustrating that mutagenesis had induced a sizeable genetic load $\left(\chi^{2}=60.88, d f=3, p<0.001\right.$; Figure 1c; Table S1 in Supporting Information). Pairwise post-hoc comparisons revealed that the regime under relaxed selection carried a larger genetic load than the monogamy and the polygamy regime, demonstrating efficient purging of deleterious mutation during experi-

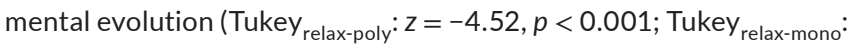
$z=-5.16, p<0.001)$. There was no difference in fertility between the monogamy and polygamy regime (Tukey poly-mono $z=-0.68$, $p=0.91$ ). All pairwise contrasts in Supporting Information Table S1.

\section{1 | Juvenile heat stress}

1.1. Elevated temperature during juvenile development strongly reduced the reproductive output of adults $\left(\chi^{2}=179.07, d f=2\right.$, $p<0.001$ ). In the control populations, a female developing at $35^{\circ} \mathrm{C}$ showed an average reduction in fertility of $32 \%$ (31 fewer offspring) compared to an untreated female, while male fertility was reduced by $22 \%$ ( 21 fewer offspring). To investigate whether the induced mutations affected TSF (defined as proportional loss of reproductive output), we first compared the effect of heat stress in the control regime and the regime evolving under relaxed selection (containing the largest genetic load; Figure 1c). We found no evidence that genetic load affected TSF $\left(\chi^{2}=3.75, d f=2, p=0.15\right)$. Strikingly, however, 
sex differences in TSF depended on selection regime (sex:regime; $\chi^{2}=14.04, d f=6, p=0.029$; Figure $\left.2 a, b\right)$. There were clear reductions in fertility via heat stress in both sexes in all but the polygamy regime, where exposed males showed no statistically significant fertility loss (Figure 2a; Table S2). To directly assess the effect of sexual selection on TSF, we compared the monogamy (natural selection) and polygamy (natural + sexual selection) regimes. This analysis confirmed the results of the global model (sex:regime; $\chi^{2}=6.96$, $d f=2, p=0.030$, Figure $2 b$ ). Heat-treated females from the polygamy regime produced significantly fewer offspring than heat-treated

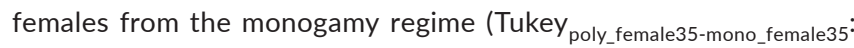
$z=-2.08, p=0.04$ ), while heat-treated polygamy males instead tended to produce more offspring than heat-treated monogamy males, although this effect was not statistically significant (Tukey poly $_{\text {_ }}$ male35-mono_male35: $z=1.41, p=0.16$ ). Full model specification and output are shown in Appendix S3.

1.2. To gain more insights into the underlying mechanisms responsible for the evolved sex difference in TSF, we ran an additional experiment on the stock population to investigate the role of repeated mating and male harassment on female TSF. Females exposed to juvenile heat stress suffered more under cohabitation with a male than females developing at benign temperature (temperature:cohabitation; $\chi^{2}=4.53, d f=1, p=0.033$, Figure 2c), which could in part explain the evolved increase in female bias of TSF observed in the polygamy regime, if polygamy males were more persistent during mating. Interestingly, there was also a
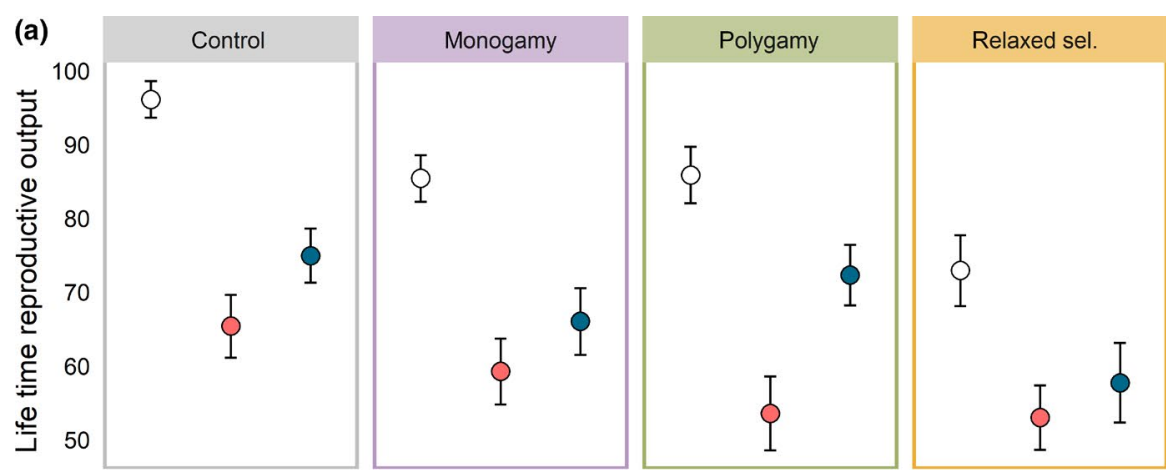

O Benign OFemale $35^{\circ} \mathrm{C}$ Male $35^{\circ} \mathrm{C}$
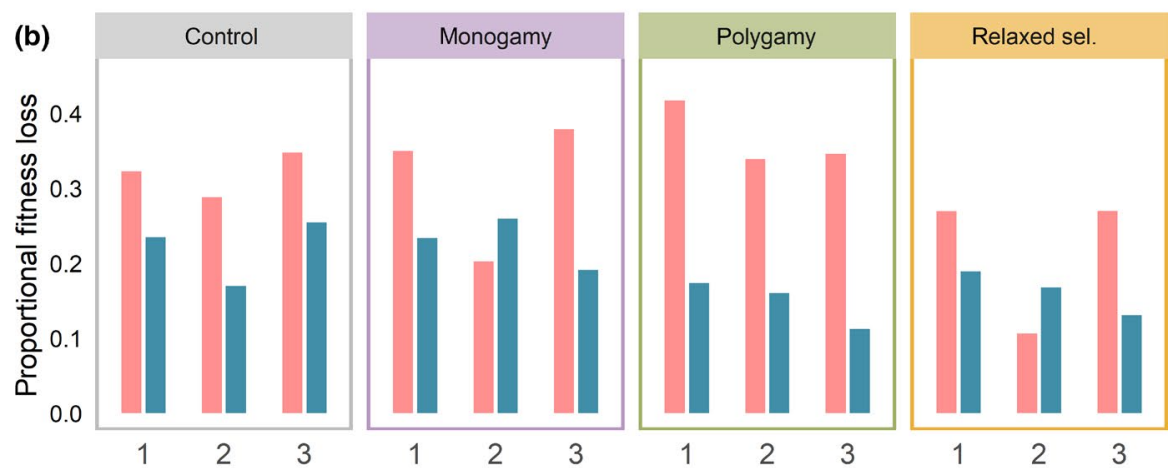

Female

Male
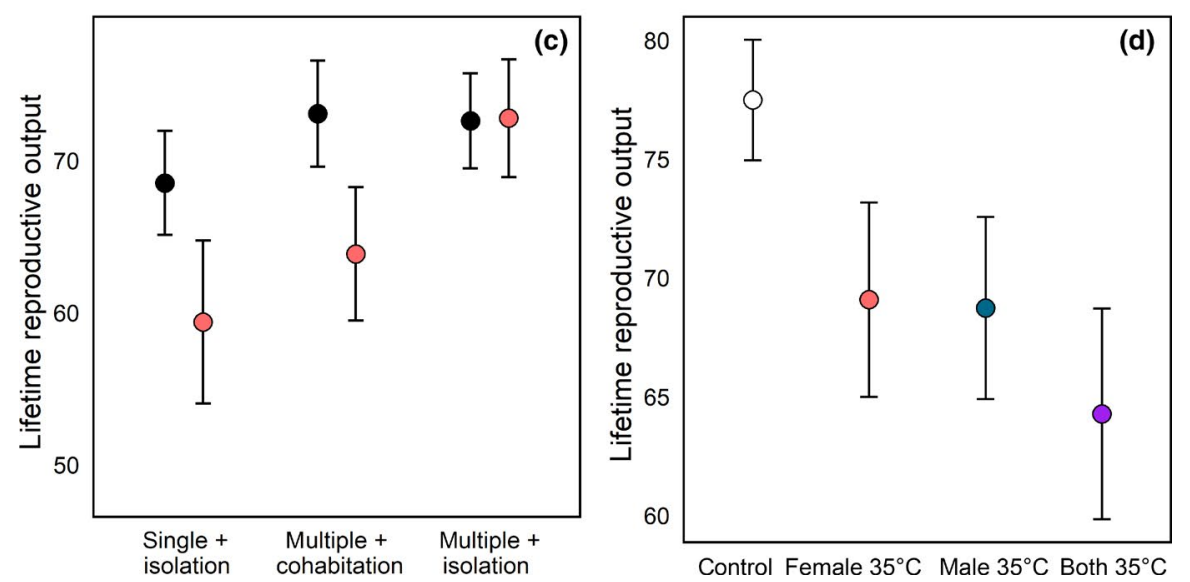

FIGURE 2 Sex differences in thermal sensitivity of fertility (TSF) under juvenile heat stress (experiments 1.1-1.3) (a) Lifetime reproductive output of couples with either the female (red symbols), the male (blue symbols), or no parent (open symbols) developing at elevated temperature. (b) Relative loss in fertility (1-stressed/control) per population. Sex differences in TSF in all three blocks are greater for polygamy populations compared to all other regimes. (c) Lifetime reproductive output of female beetles developing at benign (black symbols) or stressful (red symbols) temperature. (d) Lifetime reproductive output of pairs in which no parent (white), the female (red), the male (blue), or both parents (purple) were exposed to juvenile heat stress. Panels a, c and d show means $\pm 95 \%$ confidence intervals 
positive effect of remating, and this effect was more beneficial in females developing at elevated temperature (temperature:mating; $\left.\chi^{2}=4.99, d f=1, p=0.025\right)$. Crucially, however, the beneficial effect of remating depended strongly on the exclusion of the male between matings (Tukey single_3 35 vs. cohabitation_35 $_{3} z=-1.62$, $p=0.24$, Tukey $y_{\text {single_35 vs. remated_35 }}: z=-4.345, p<0.0001$, Figure 2c); and strikingly, remating with experimental exclusion of the male between matings sufficed to completely thwart the negative effect of developmental temperature stress in females

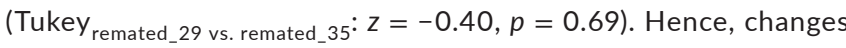
in the relative costs and benefits of multiple mating between the polygamy and monogamy regime are likely a driver of the evolved sex difference in TSF.

1.3. We also explored whether the effect of males on female TSF was dependent on whether males had also been exposed to heat, as might be the more common situation in natural populations. As expected, we found strong effects of both male and female developmental heat stress (Female: $\chi^{2}=11.98, d f=1$, $p<0.001$; Male: $\chi^{2}=10.75, d f=1, p=0.001$; Figure 2d). The interaction between female and male heat stress, however, was non-significant $\left(\chi^{2}=0.72, d f=1, p=0.40\right)$, suggesting that the effects of female and male juvenile heat stress on TSF are mostly additive. This result might be explained by heat stress reducing the expression of male traits with antagonistic effects on female TSF (level of male harm and beneficial ejaculate compounds) to similar extent.

\section{2 | Effects of adult heat shock}

2.1. The adult heat shock treatment led to an overall loss of fertility $\left(\chi^{2}=17.17, d f=2, p<0.001\right)$ even though its impact was much weaker compared to the impact of juvenile heat stress (average fertility loss for females was $10.2 \%$ and for males $4.2 \%$ ). The effect of heat shock was significantly stronger in females (Tukey $_{\text {female - male: }}$ $z=-2.38, p=0.045)$ and, in fact, not statistically detectable in

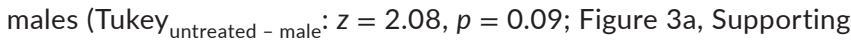
Information Table S2). The effect of heat shock was generally too weak to be detected when analysing subsets of the data (results not shown), resulting in neither the induced genetic load (regime control vs. relaxed:treated sex: $\chi^{2}=0.44, d f=2, p=0.88$ ) nor sexual selection (regime polygamy vs. monogamy $_{\text {: }}$ treated sex: $\chi^{2}=0.43, d f=2, p=0.81$ ) having a statistically significant effect on TSF. Full model specification and output are shown in Appendix S4.

2.2. To elucidate underlying mechanisms explaining sex differences in TSF under adult heat shock, we analysed effects of male recovery, in terms of both time and remating (inducing ejaculate renewal) after heat shock. Our data show that male beetles can recover almost completely from the applied heat shock treatment within a 26-hr recovery period. Males showed strong TSF, signified by an $15 \%$ reduction in fertility compared to the untreated control group, when mating within $2 \mathrm{hr}$ after heat shock (Tukey untreated $-2 \mathrm{hr}: \mathrm{z}=2.91, p=0.01$, Figure $3 \mathrm{~b}$ ). If males were given $26 \mathrm{hr}$ of recovery in isolation, however, no significant effect on fertility could be found (Tukey $_{\text {untreated }-26 \mathrm{hr}}$ :
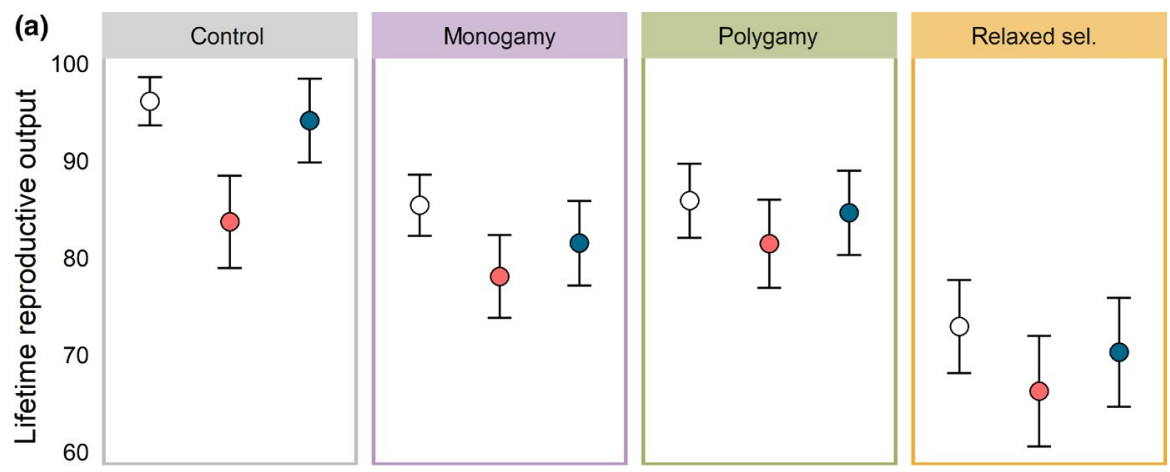

FIGURE 3 Sex differences in thermal sensitivity of fertility (TSF) under adult heat shock (Experiments $2.1 \& 2.2$ ) (a) Lifetime reproductive output depending on the sex that underwent adult heat shock (HS). (b) Recovery of male fertility after adult heat shock. (c) Lifetime reproductive output of untreated (black) and heat-shocked (blue) males that were mated to a virgin female $2 \mathrm{hr}$ after the treatment and again, to a second female, $26 \mathrm{hr}$ after the treatment. All panels show means $\pm 95 \%$ confidence intervals
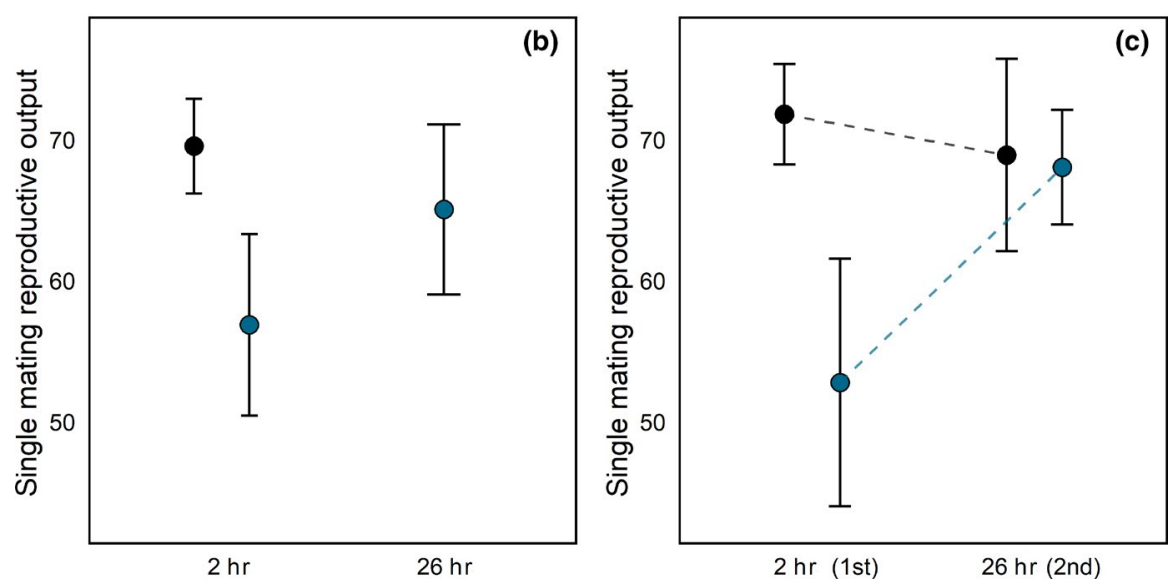
$z=1.27, p=0.41$; Figure $3 b)$. Similarly, there was no reduction in fertility in beetles that mated a second time $26 \mathrm{hr}$ after the treatment

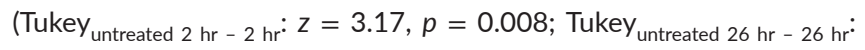
$z=0.053, p=0.99$; Figure $3 c$ ). Recovery of males with or without remating showed similar effects on TSF (Tukey treated $26 \mathrm{hr}$ mate - treated 26 $h r$ isolated $z=0.68, p=0.50$ ), suggesting that timing is crucial when assessing TSF, and that realized sex differences in TSFs in natural populations are state-dependent properties of mating system and ecology.

\section{3 | Comparing intraspecific and interspecific variation in sex differences in TSF}

To put our results into perspective, we performed a (non-exhaustive) literature search for studies on other insects that had estimated effects of heat stress on both male and female fertility (extended methods in Appendix S5 and a list of included studies and estimates is presented in Supporting Information Table S6). This allowed us to calculate and compare standardized estimates of sex differences in TSF (Figure 4). The variability in this estimate obtained by manipulating mating system parameters and the timing of heat stress relative to (re)mating in our study (mean TSF $\pm 1 S D: 0.11 \pm 0.93$ ) roughly correspond to that reported between species in previously published studies $(0.20 \pm 1.01)$, demonstrating that the mating system can be a main determinate of sex differences in TSF. Moreover, in contrast to occasional claims of male-biased TSF, there is no such consistent bias in the reviewed studies on insects estimating male and female TSF under the same experimental conditions.

\section{4 | DISCUSSION}

In this study, we have demonstrated that the mating system can affect sex differences in TSF using the seed beetle $C$. maculatus.
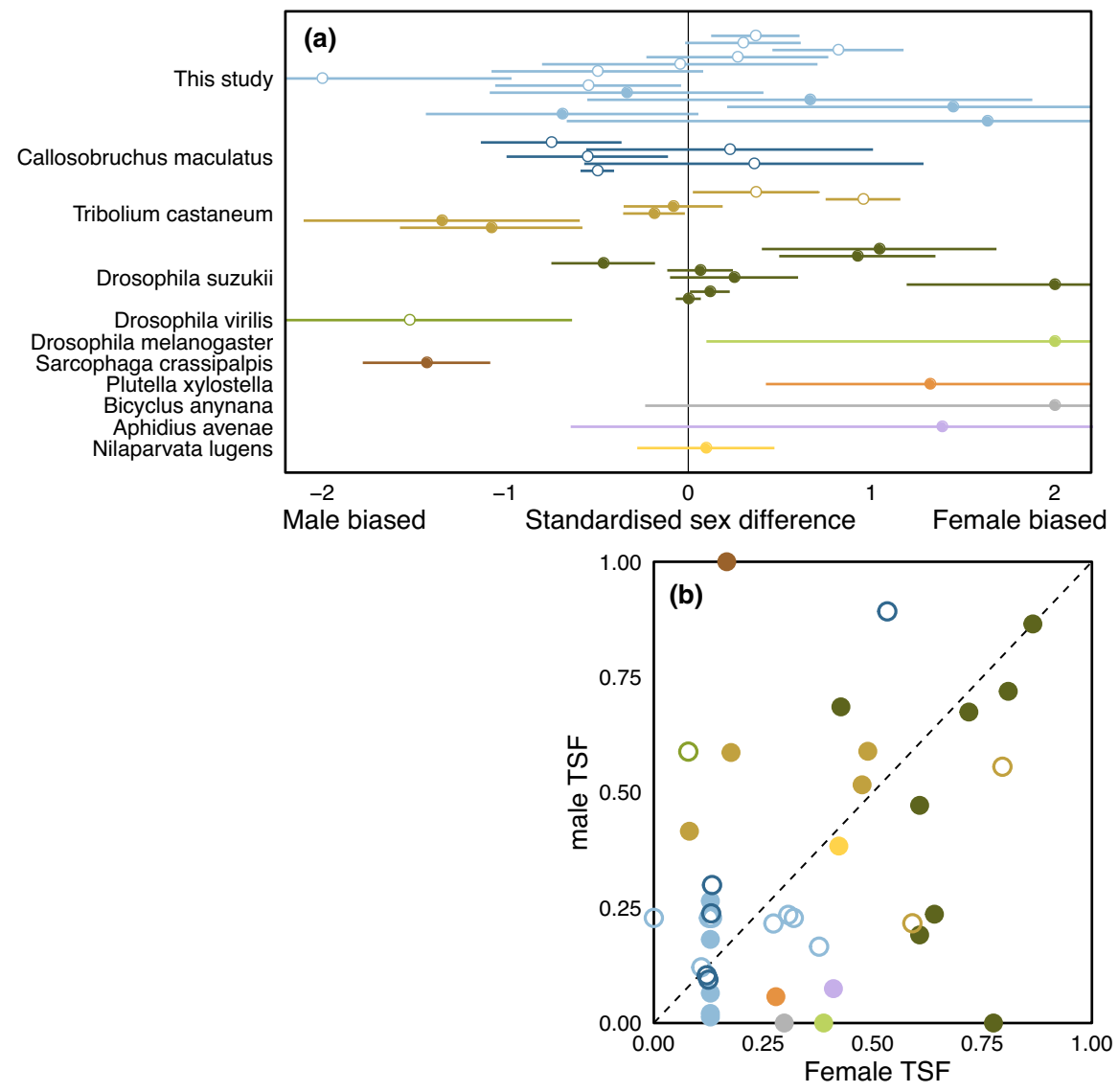

FIGURE 4 Intraspecific variation in the sex difference in thermal sensitivity of fertility (TSF) generated through manipulation of the mating system and timing of heat stress relative to (re)mating in this study, compared to estimates from other studies on insects. Open symbols represent heat treatments applied at a juvenile stage while closed symbols represent heat treatments applied during the adult stage. (a) A standardized measure of the sex difference in TSF was calculated as: $\mathrm{SD}_{\mathrm{TSF}}=\left(\mathrm{TSF}_{\text {female }}-\mathrm{TSF}_{\text {male }}\right) /\left(\left(\mathrm{TSF} \mathrm{female}_{\text {fe }}+\mathrm{TSF}_{\text {male }}\right) / 2\right)$, where TSF is the relative fertility loss due to heat stress (1-benign/stress). A given $\mathrm{SD}_{\mathrm{TSF}}$ from this study was derived by first calculating the TSF of one sex in a given experimental condition (e.g. TSF female with remating but no cohabitation from experiment 1.2) and then always using the TSF observed in one of the two main experiments (1.1 for juvenile stress and 2.1 for adult stress) for the opposite sex from control populations as comparison (e.g. TSF $_{\text {male }}$ from experiment 1.1). 95\% confidence intervals were calculated through propagation of the uncertainty reported for measures of reproductive output within the respective studies. (b) Comparison of male and female TSF for the studies presented in panel a. Further details, including inclusion criteria for reviewed studies and a table of all values, are presented in Supporting Information Appendix S5and Table S6 
Strikingly, sexual selection on induced mutations over only two generations of experimental evolution led to increased female bias in TSF in polygamous populations experiencing developmental heat stress. Male harassment aggravated the negative effects of heat stress on females, suggesting that stronger effects of male harassment might explain the increased female bias in TSF in polygamous experimental populations. In C. maculatus, sexual selection in males is more than three times as effective at purging deleterious alleles compared to fecundity selection on females under semi-natural laboratory setting, as used here (Grieshop et al., 2016, 2021). One plausible mechanism behind the result is therefore that sexual selection in the polygamous mating regime led to more efficient purging of alleles with deleterious effects on male mating success, relative to purging of alleles with deleterious effects on female viability and fertility. This could potentially shift the balance between male persistence and female resistance during (re)mating interactions. Male-biased selection on deleterious alleles can also improve population fitness by sparing females the cost of adaptation (Agrawal, 2001; Agrawal \& Whitlock, 2010; Manning, 1984), if some of the deleterious alleles in males also have deleterious effects in females (Andersson, 1994; Bonduriansky \& Chenoweth, 2009; Rowe \& Houle, 1996; Tomkins et al., 2004), for which there is evidence in $C$. maculatus (Grieshop et al., 2021). However, once males and females in the polygamous populations are engaged in mating interactions, the heightened genetic quality of male genotypes evolving under strong sexual selection may have resulted in increased male harassment of females, and the negative effects of this sexual conflict may have been exposed under female heat stress. In nature, the relative extent of this negative effect should strongly depend on ecological settings and population densities modulating the degrees of conflict (Arbuthnott et al., 2014; Gomez-Llano et al., 2018; MacPherson et al., 2018; Yun et al., 2017), and the fact that males and females will often have experienced heat stress simultaneously. We also note that our comparison of monogamous and polygamous populations evolving from inflated levels of mutational variation does not describe a natural scenario of long-term evolution in populations under mutation-selection balance. Instead, our approach was designed to demonstrate that (sex-specific) natural and sexual selection can act on gen etic variation to shape TSF. Hence, our study provides a proof-of-principle for a direct link between the mating system and sex differences in TSF.

At present, the scant literature available seems to suggest that male reproduction is more sensitive to heat stress than female reproduction (David etal., 2005; Porcelli et al., 2017; Sales et al., 2018), and male fertility has also been demonstrated to be very temperature sensitive in C. maculatus (Berger et al., 2014; MartinossiAllibert, Rueffler, et al., 2019; Martinossi-Allibert, Thilliez, et al., 2019; Vasudeva et al., 2014, 2021). Our data show that C. maculatus females can in fact be more strongly affected by heat stress, and that the realized TSF in males and females can be highly contingent on the experimental design (see also Terblanche et al., 2007) and mating system parameters such as the extent of sexual conflict and remating rates. For example, the adult heat shock treatment resulted in relatively weak effects on fertility, but with significant female bias in TSF. However, our additional experiment showed that male fertility is very sensitive within the first hours following heat shock but can fully recover over an additional 24-hr period, implying that the sex bias in TSF in adults is likely to change throughout life following heat exposure. In the case of juvenile heat stress, male harassment aggravated the effects of heat stress on female fertility, while repeated mating instead had positive effects on both male and female TSF. However, the size of the nuptial gift provided by male $C$. maculatus has been found to decrease with temperature, suggesting that this male compensatory effect may diminish when also males are heat stressed (Fox et al., 2006). Other studies on fruit flies (García-Roa et al., 2019) and C. maculatus (Martinossi-Allibert, Rueffler, et al., 2019; Martinossi-Allibert, Thilliez, et al., 2019) have concluded that heat stress generally reduces the female fertility cost of male cohabitation. In both these studies, the impact of sexual conflict was assessed directly in the stressful environment when both sexes were stressed, while in the present study the effects of mating interactions on fertility were measured in a benign environment after heat stress had been applied to one, or both sexes. Collectively, this limited set of studies suggest that there is a multitude of ways that temperature can modulate the consequences of sexual selection and conflict (García-Roa et al., 2020), and conversely, that sexual selection and conflict can shape sensitivity to temperature (MartinossiAllibert, Rueffler, et al., 2019; Martinossi-Allibert, Thilliez, et al., 2019; Parrett \& Knell, 2018). Depending on population density, mating system and heat stress characteristics, laboratory experiments may thus lead to erroneous estimates of TSFs, and in extension, misjudgements of the threat on population growth imposed by climate warming, even when efforts are made to measure TSF sex specifically. Indeed, our comparison of variation in sex differences in TSF generated by mating system parameters in our study, to that reported between species (Figure 4), suggests that TSF is a highly dynamic property that responds to population structure and ecological changes. Predicting the impact of such factors affecting TSF in natural populations is likely extremely difficult due to spatial and temporal variation in population dynamics and densities, but we urge researchers undertaking efforts to establish base values for sex-specific TSF of species under laboratory settings to appreciate how small details of the experimental design can fundamentally alter the results.

Directly comparing the effects of our two heat stress treatments is difficult as they were applied with different intensities over different time frames and life stages. Nevertheless, juvenile heat stress is known to affect the development of reproductive organs and result in reduced sperm numbers in insects (Chirault et al., 2015; Kirk Green et al., 2019; Nguyen et al., 2013; Vasudeva et al., 2014). Vasudeva et al. (2014), found not only a decrease in sperm number but also a reduction in relative testis size by almost $25 \%$ in C. maculatus males exposed to similar juvenile heat stress as in our experiment. In a later study, the same authors determined the first $20 \%$ of larval development to be the most temperature-sensitive period of testis development (Vasudeva et al., 2021). A recent study using the flour beetle 
Tribolium castaneum found that the most sensitive phase of testis development is likely during the pupal stage and that testis size can be almost complete recovered in males exposed to heat stress at an immature adult stage (Sales et al., 2021). Together, these studies suggest that there are several time points with heightened temperature sensitivity throughout male reproductive development. Heat shock treatments applied on adults have also been found to decrease numbers of transferred sperm and reduce fertility (Chevrier et al., 2019; Sales et al., 2018, 2021), but considering the data presented here and in Sales et al. (2021), such effects may be reversible in most cases. Similar changes in the morphology of female reproductive organs (i.e. smaller ovaries) combined with a strong reduction in egg number have also been reported for flies of the species Drosophila suzukii developing at elevated temperature (Kirk Green et al., 2019). However, little is known about the ability of female reproduction to recover from heat stress. Data from an experiment exposing newly emerged cotton bollworm females, Helicoverpa armigera, to a range of heat shock treatments show a postponement of peak reproduction correlated to the treatment intensity, suggesting some recovery processes taking place between the heat shock event and the onset of reproduction (Mironidis \& Savopoulou-Soultani, 2010). In summary, this suggest that, at least in holometabolous insects, heat stress during development can cause an impairment of reproductive organs which is only reversible given a considerable amount of recovery time in a benign environment (if at all), while heat shock experienced at the adult life stage might be reversible on shorter time-scales. Importantly, however, we also show that strategies such as remating or postponement of reproduction may mitigate the impact of heat stress experienced both early and late in life.

Inducible compensatory responses that buffer the effects of heat stress are costly and may therefore depend on the genetic quality of the organism. Moreover, it has recently been shown that elevated temperatures can aggravate the deleterious effect of mutations (Berger et al., 2021). We therefore predicted that populations with larger genetic loads might show increased TSF but found no support for this in our data. The model applied by Berger et al. (2021) predicts that temperature-dependent increases in mutational effects stem from reversible misfolding of proteins at high temperature. It is possible that such effects were no longer apparent following heat stress in our experiment as individuals were shifted back to benign temperature (i.e. temperature-sensitive mutants either died during development or survived and got 'rescued' by being placed at benign temperature). Indeed, individuals surviving short-term heat stress may even elicit compensatory stress responses that mitigate deleterious effects of mutations (Casanueva et al., 2012). Additionally, as we here studied temperature effects in the adult stage, where realized TSFs are consequences of mating interactions, it is possible that a weakening of sexually antagonistic interactions in populations with large genetic loads (and low-condition individuals) may have contributed to mitigating the detrimental effects of temperature. Indeed, a general tenet highlighted throughout this study of how frequency-dependent processes in general (Bolnick et al., 2011; Brady et al., 2019; Dall et al., 2012; Svensson \& Connallon, 2019), and sexual selection in particular (Chenoweth et al., 2015; GarcíaRoa et al., 2020; MacPherson et al., 2018; Martinossi-Allibert, Rueffler, et al., 2019; Martinossi-Allibert, Thilliez, et al., 2019; Rankin et al., 2011; Yun et al., 2017) may affect population vulnerability and adaptation to abiotic factors.

\section{ACKNOWLEDGEMENTS}

We would like to thank Elena Mondino for help with the illustration of the experimental design, Johanna Liljestrand Rönn for help in the laboratory, and Bo Stenerlöw and Olga Vorontsova for help with the irradiation. This research was funded by grants from the Swedish research council (VR: 2015-05223 and 2019-05024) and Carl Tryggers Stiftelse (CTS:18:32) to D.B.

\section{CONFLICT OF INTEREST}

The authors declare no conflict of interest.

\section{AUTHORS' CONTRIBUTIONS}

J.B., D.B. and M.K. conceived the ideas and designed the experiments; J.B., D.J., P.M. and M.K. collected the data; J.B. analysed the data and led the writing of the manuscript with assistance from D.B. and M.K.; J.B., D.B. and M.K. contributed critically to the drafts and all authors gave final approval for publication.

\section{DATA AVAILABILITY STATEMENT}

All data presented in this manuscript are archived and publicly available on Dryad Digital Repository under the following https://doi. org/10.5061/dryad.kkwh70s5k, (Baur et al., 2021).

\section{ORCID}

Julian Baur (iD https://orcid.org/0000-0002-4739-2756

Mareike Koppik iD https://orcid.org/0000-0002-3433-7248

David Berger (ID https://orcid.org/0000-0003-0196-6109

\section{REFERENCES}

Agrawal, A. F. (2001). Sexual selection and the maintenance of sexual reproduction. Nature, 411, 692-695. https://doi. org/10.1038/35079590.

Agrawal, A. F., \& Whitlock, M. C. (2010). Environmental duress and epistasis: How does stress affect the strength of selection on new mutations? Trends in Ecology \& Evolution, 25(8), 450-458. https://doi. org/10.1016/j.tree.2010.05.003.

Andersson, M. (1994). Sexual selection (Vol. 72). Princeton University Press. https://doi.org/10.2307/j.ctvs32s1x

Angilletta, M. J. (2009). Thermal adaptation: A theoretical and empirical synthesis. Oxford University Press. https://doi.org/10.1093/acpro f:oso/9780198570875.001.1

Arbuthnott, D., Dutton, E. M., Agrawal, A. F., \& Rundle, H. D. (2014). The ecology of sexual conflict: Ecologically dependent parallel evolution of male harm and female resistance in Drosophila melanogaster. Ecology Letters, 17(2), 221-228. https://doi.org/10.1111/ele.12222

Arnqvist, G., \& Nilsson, T. (2000). The evolution of polyandry: Multiple mating and female fitness in insects. Animal Behaviour, 60(2), 145164. https://doi.org/10.1006/anbe.2000.1446

Arnqvist, G., Nilsson, T., \& Katvala, M. (2004). Mating rate and fitness in female bean weevils. Behavioral Ecology, 16(1), 123-127. https://doi. org/10.1093/beheco/arh119 
Arnqvist, G., \& Rowe, L. (2005). Sexual conflict. Princeton University Press. Retrieved from https://books.google.se/books?id=JLfvw PqsHnMC

Bagchi, B., Corbel, Q., Khan, I., Payne, E., Banerji, D., Liljestrand-Rönn, J., Martinossi-Allibert, I., Baur, J., Sayadi, A., Immonen, E., Arnqvist, G., Söderhäll, I., \& Berger, D. (2021). Sexual conflict drives micro- and macroevolution of sexual dimorphism in immunity. BMC Biology, 19(1), 114. https://doi.org/10.1186/s12915-021-01049-6

Bates, D., Mächler, M., Bolker, B., \& Walker, S. (2015). Fitting linear mixed-effects models using Ime4. Journal of Statistical Software, 67(1), 1-48. https://doi.org/10.18637/jss.v067.i01

Bathiany, S., Dakos, V., Scheffer, M., \& Lenton, T. M. (2018). Climate models predict increasing temperature variability in poor countries. Science Advances, 4(5), eaar5809. https://doi.org/10.1126/sciadv. aar5809

Baur, J., \& Berger, D. (2020). Experimental evidence for effects of sexual selection on condition-dependent mutation rates. Nature Ecology \& Evolution, 4(5), 737-744. https://doi.org/10.1038/s4155 9-020-1140-7

Baur, J., Jagusch, D., Michalak, P., Koppik, M., \& Berger, D. (2021). Data from: The mating system affects the temperature sensitivity of male and female fertility. Dryad Digital Repository, https://doi. org/10.5061/dryad.kkwh70s5k

Baur, J., Nsanzimana, J. D'. A., \& Berger, D. (2019). Sexual selection and the evolution of male and female cognition: A test using experimental evolution in seed beetles. Evolution, 73(12), 2390-2400. https:// doi.org/10.1111/evo.13793

Bayram, H., Sayadi, A., Immonen, E., \& Arnqvist, G. (2019). Identification of novel ejaculate proteins in a seed beetle and division of labour across male accessory reproductive glands. Insect Biochemistry and Molecular Biology, 104, 50-57. https://doi.org/10.1016/j. ibmb.2018.12.002

Berger, D., Grieshop, K., Lind, M. I., Goenaga, J., Maklakov, A. A., \& Arnqvist, G. (2014). Intralocus sexual conflict and environmental stress. Evolution, 68(8), 2184-2196. https://doi.org/10.1111/ evo.12439

Berger, D., Stångberg, J., Baur, J., \& Walters, R. J. (2021). Elevated temperature increases genome-wide selection on de novo mutations. Proceedings of the Royal Society B: Biological Sciences, 288(1944), 20203094. https://doi.org/10.1098/rspb.2020.3094

Berger, D., Walters, R. J., \& Gotthard, K. (2008). What limits insect fecundity? Body size- and temperature-dependent egg maturation and oviposition in a butterfly. Functional Ecology, 22(3), 523-529. https://doi.org/10.1111/j.1365-2435.2008.01392.x

Berger, D., You, T., Minano, M. R., Grieshop, K., Lind, M. I., Arnqvist, G., \& Maklakov, A. A. (2016). Sexually antagonistic selection on genetic variation underlying both male and female same-sex sexual behavior. BMC Evolutionary Biology, 16(1), 88. https://doi.org/10.1186/ s12862-016-0658-4

Bolnick, D. I., Amarasekare, P., Araújo, M. S., Bürger, R., Levine, J. M., Novak, M., Rudolf, V. H. W., Schreiber, S. J., Urban, M. C., \& Vasseur, D. A. (2011). Why intraspecific trait variation matters in community ecology. Trends in Ecology \& Evolution, 26(4), 183-192. https://doi. org/10.1016/j.tree.2011.01.009

Bonduriansky, R., \& Chenoweth, S. F. (2009). Intralocus sexual conflict. Trends in ecology \& evolution, 24(5), 280-288. https://doi. org/10.1016/j.tree.2008.12.005.

Brady, S. P., Bolnick, D. I., Angert, A. L., Gonzalez, A., Barrett, R. D. H., Crispo, E., Derry, A. M., Eckert, C. G., Fraser, D. J., Fussmann, G. F., Guichard, F., Lamy, T., McAdam, A. G., Newman, A. E. M., Paccard, A., Rolshausen, G., Simons, A. M., \& Hendry, A. P. (2019). Causes of maladaptation. Evolutionary Applications, 12(7), 1229-1242. https://doi.org/10.1111/eva.12844

Bubliy, O. A., Kristensen, T. N., Kellermann, V., \& Loeschcke, V. (2012). Humidity affects genetic architecture of heat resistance in
Drosophila melanogaster. Journal of Evolutionary Biology, 25(6), 1180-1188. https://doi.org/10.1111/j.1420-9101.2012.02506.x

Casanueva, M. O., Burga, A., \& Lehner, B. (2012). Fitness trade-offs and environmentally induced mutation buffering in isogenic $C$. elegans. Science (New York, N.Y.), 335(6064), 82-85. https://doi.org/10.1126/ science.1213491

Caswell, H. (2006). Matrix population models. In Encyclopedia of environmetrics: American Cancer Society. https://doi.org/10.1002/97804 70057339.vam006m

Chenoweth, S. F., Appleton, N. C., Allen, S. L., \& Rundle, H. D. (2015). Genomic evidence that sexual selection impedes adaptation to a novel environment. Current Biology, 25(14), 1860-1866. https://doi. org/10.1016/j.cub.2015.05.034

Chevin, L.-M., Collins, S., \& Lefèvre, F. (2013). Phenotypic plasticity and evolutionary demographic responses to climate change: Taking theory out to the field. Functional Ecology, 27(4), 967-979. https://doi. org/10.1111/j.1365-2435.2012.02043.x

Chevrier, C., Nguyen, T. M., \& Bressac, C. (2019). Heat shock sensitivity of adult male fertility in the parasitoid wasp Anisopteromalus calandrae (Hymenoptera, Pteromalidae). Journal of Thermal Biology, 85, 102419. https://doi.org/10.1016/j.jtherbio.2019.102419

Chirault, M., Lucas, C., Goubault, M., Chevrier, C., Bressac, C., \& Lécureuil, C. (2015). A combined approach to heat stress effect on male fertility in Nasonia vitripennis: From the physiological consequences on spermatogenesis to the reproductive adjustment of females mated with stressed males. PLoS One, 10(3), e0120656. https://doi. org/10.1371/journal.pone.0120656

Chirgwin, E., Connallon, T., \& Monro, K. (2021). The thermal environment at fertilization mediates adaptive potential in the sea. Evolution Letters, 5(2), 154-163. https://doi.org/10.1002/ evl3.215

Crudgington, H. S., \& Siva-Jothy, M. T. (2000). Genital damage, kicking and early death. Nature, 407(6806), 855-856. https://doi. org/10.1038/35038154

Dall, S. R. X., Bell, A. M., Bolnick, D. I., \& Ratnieks, F. L. W. (2012). An evolutionary ecology of individual differences. Ecology Letters, 15(10), 1189-1198. https://doi.org/10.1111/j.1461-0248.2012.01846.x

David, J. R., Araripe, L. O., Chakir, M., Legout, H., Lemos, B., Pétavy, G., Rohmer, C., Joly, D., \& Moreteau, B. (2005). Male sterility at extreme temperatures: A significant but neglected phenomenon for understanding Drosophila climatic adaptations. Journal of Evolutionary Biology, 18(4), 838-846. https://doi.org/10.1111/j.1420-9101.2005.00914.x

Degioanni, A., Bonenfant, C., Cabut, S., \& Condemi, S. (2019). Living on the edge: Was demographic weakness the cause of Neanderthal demise? PLoS One, 14(5), e0216742. https://doi.org/10.1371/journ al.pone. 0216742

Dell, A. I., Pawar, S., \& Savage, V. M. (2011). Systematic variation in the temperature dependence of physiological and ecological traits. Proceedings of the National Academy of Sciences of the United States of America, 108(26), 10591-10596. https://doi.org/10.1073/ pnas. 1015178108

Deutsch, C. A., Tewksbury, J. J., Huey, R. B., Sheldon, K. S., Ghalambor, C. K., Haak, D. C., \& Martin, P. R. (2008). Impacts of climate warming on terrestrial ectotherms across latitude. Proceedings of the National Academy of Sciences of the United States America, 105(18), 66686672. https://doi.org/10.1073/pnas.0709472105

Deutscher Wetterdienst. (n.d.). Klimatafel von Lomé (Flugh.)/Togo. Retrieved from https://www.dwd.de/DWD/klima/beratung/ak/ ak_653870_kt.pdf

Dougherty, L. R., van Lieshout, E., McNamara, K. B., Moschilla, J. A., Arnqvist, G., \& Simmons, L. W. (2017). Sexual conflict and correlated evolution between male persistence and female resistance traits in the seed beetle Callosobruchus maculatus. Proceedings of the Royal Society B: Biological Sciences, 284(1855), 20170132. https:// doi.org/10.1098/rspb.2017.0132 
Dowling, D. K., \& Simmons, L. W. (2009). Reactive oxygen species as universal constraints in life-history evolution. Proceedings of the Royal Society B: Biological Sciences, 276(1663), 1737-1745. https://doi. org/10.1098/rspb.2008.1791

Eady, P. E. (1995). Why do male Callosobruchus maculatus beetles inseminate so many sperm? Behavioral Ecology and Sociobiology, 36(1), 2532. https://doi.org/10.1007/s002650050121

Edvardsson, M., \& Tregenza, T. (2005). Why do male Callosobruchus maculatus harm their mates? Behavioral Ecology, 16(4), 788-793. https:// doi.org/10.1093/beheco/ari055

Feder, M. E., Bennett, A. F., \& Huey, R. B. (2000). Evolutionary physiology. Annual Review of Ecology and Systematics, 31(1), 315-341. https://doi.org/10.1146/annurev.ecolsys.31.1.315

Fox, C. W. (1993). Multiple mating, lifetime fecundity and female mortality of the Bruchid beetle, Callosobruchus maculatus (Coleoptera: Bruchidae). Functional Ecology, 7(2), 203-208. https://doi. org $/ 10.2307 / 2389888$

Fox, C. W., Stillwell, R. C., Wallin, W. G., \& Hitchcock, L. J. (2006). Temperature and host species affect nuptial gift size in a seedfeeding beetle. Functional Ecology, 20(6), 1003-1011. https://doi. org/10.1111/j.1365-2435.2006.01197.x

Fox, J., \& Weisberg, S. (2019). An R companion to applied regression (Third). Sage. Retrieved from https://socialsciences.mcmaster.ca/jfox/ Books/Companion/

Frazier, M. R., Huey, R. B., \& Berrigan, D. (2006). Thermodynamics constrains the evolution of insect population growth rates: "Warmer Is Better". The American Naturalist, 168(4), 512-520. https://doi. org/10.1086/506977

Gage, M. J. G., Macfarlane, C. P., Yeates, S., Ward, R. G., Searle, J. B., \& Parker, G. A. (2004). Spermatozoal traits and sperm competition in Atlantic salmon: Relative sperm velocity is the primary determinant of fertilization success. Current Biology, 14(1), 44-47. https://doi. org/10.1016/j.cub.2003.12.028

García-Roa, R., Chirinos, V., \& Carazo, P. (2019). The ecology of sexual conflict: Temperature variation in the social environment can drastically modulate male harm to females. Functional Ecology, 33(4), 681-692. https://doi.org/10.1111/1365-2435.13275

García-Roa, R., Garcia-Gonzalez, F., Noble, D. W. A., \& Carazo, P. (2020). Temperature as a modulator of sexual selection. Biological Reviews, 95(6), 1607-1629. https://doi.org/10.1111/brv.12632

Gay, L., Hosken, D. J., Vasudeva, R., Tregenza, T., \& Eady, P. E. (2009). Sperm competition and maternal effects differentially influence testis and sperm size in Callosobruchus maculatus. Journal of Evolutionary Biology, 22(5), 1143-1150. https://doi. org/10.1111/j.1420-9101.2009.01724.x

Gerking, S. D., \& Lee, R. M. (1983). Thermal limits for growth and reproduction in the Desert PupfishCyprinodon n. nevadensis. Physiological Zoology, 56(1), 1-9. https://doi.org/10.1086/physz ool.56.1.30159959

Godwin, J. L., Lumley, A. J., Michalczyk, Ł., Martin, O. Y., \& Gage, M. J. G. (2020). Mating patterns influence vulnerability to the extinction vortex. Global Change Biology, 26(8), 4226-4239. https://doi. org/10.1111/gcb.15186

Gomez-Llano, M. A., Bensch, H. M., \& Svensson, E. I. (2018). Sexual conflict and ecology: Species composition and male density interact to reduce male mating harassment and increase female survival. Evolution, 72(4), 906-915. https://doi.org/10.1111/evo.13457

Gómez-Llano, M., Scott, E., \& Svensson, E. I. (2020). The importance of pre- and postcopulatory sexual selection promoting adaptation to increasing temperatures. Current Zoology, 67(3), 321-327. https:// doi.org/10.1093/cz/zoaa059

Grieshop, K., Maurizio, P. L., Arnqvist, G., \& Berger, D. (2021). Selection in males purges the mutation load on female fitness. Evolution Letters, 5(4), 328-343. https://doi.org/10.1002/evl3.239
Grieshop, K., Stångberg, J., Martinossi-Allibert, I., Arnqvist, G., \& Berger, D. (2016). Strong sexual selection in males against a mutation load that reduces offspring production in seed beetles. Journal of Evolutionary Biology, 29(6), 1201-1210. https://doi.org/10.1111/ jeb.12862

Hansen, P. J. (2009). Effects of heat stress on mammalian reproduction. Philosophical Transactions of the Royal Society B: Biological Sciences, 364(1534), 3341-3350. https://doi.org/10.1098/ rstb.2009.0131

Haren, M. M. V., Rönn, J. L., Schilthuizen, M., \& Arnqvist, G. (2017). Postmating sexual selection and the enigmatic jawed genitalia of Callosobruchus subinnotatus. Biology Open, 6(7), 1008-1012. https://doi.org/10.1242/bio.025684

Haldane, J. B. S. (1957). The cost of natural selection. Journal of Genetics, 55(3), 511. https://doi.org/10.1007/BF02984069

Helfenstein, F., Losdat, S., Møller, A. P., Blount, J. D., \& Richner, H. (2010). Sperm of colourful males are better protected against oxidative stress. Ecology Letters, 13(2), 213-222. https://doi. org/10.1111/j.1461-0248.2009.01419.x

Hoffmann, A. A. (2010). Physiological climatic limits in Drosophila: Patterns and implications. Journal of Experimental Biology, 213(6), 870-880. https://doi.org/10.1242/jeb.037630

Hoffmann, A. A., Chown, S. L., \& Clusella-Trullas, S. (2013). Upper thermal limits in terrestrial ectotherms: How constrained are they? Functional Ecology, 27(4), 934-949. https://doi. org/10.1111/j.1365-2435.2012.02036.x

Hoffmann, A. A., \& Sgrò, C. M. (2011). Climate change and evolutionary adaptation. Nature, 470(7335), 479-485. https://doi.org/10.1038/ nature09670

Hosken, D. J., Garner, T. W. J., Tregenza, T., Wedell, N., \& Ward, P. I. (2003). Superior sperm competitors sire higher-quality young. Proceedings of the Royal Society of London. Series B: Biological Sciences, 270(1527), 1933-1938. https://doi.org/10.1098/rspb.2003.2443

Hotzy, C., \& Arnqvist, G. (2009). Sperm competition favors harmful males in seed beetles. Current Biology, 19(5), 404-407. https://doi. org/10.1016/j.cub.2009.01.045

Iossa, G. (2019). Sex-specific differences in thermal fertility limits. Trends in Ecology \& Evolution, 34(6), 490-492. https://doi.org/10.1016/j. tree.2019.02.016

Johnson, N. C., Xie, S.-P., Kosaka, Y., \& Li, X. (2018). Increasing occurrence of cold and warm extremes during the recent global warming slowdown. Nature Communications, 9(1), 1724. https://doi.org/10.1038/ s41467-018-04040-y

Jørgensen, K. T., Sørensen, J. G., \& Bundgaard, J. (2006). Heat tolerance and the effect of mild heat stress on reproductive characters in Drosophila buzzatii males. Journal of Thermal Biology, 31(3), 280286. https://doi.org/10.1016/j.jtherbio.2005.11.026

Karlsson, B., Leimar, O., \& Wiklund, C. (1997). Unpredictable environments, nuptial gifts and the evolution of sexual size dimorphism in insects: An experiment. Proceedings of the Royal Society of London. Series B: Biological Sciences, 264(1381), 475-479. https://doi. org/10.1098/rspb.1997.0068

Kellermann, V., \& van Heerwaarden, B. (2019). Terrestrial insects and climate change: Adaptive responses in key traits. Physiological Entomology, 44(2), 99-115. https://doi.org/10.1111/phen.12282

Kingsolver, J. G., \& Huey, R. B. (2008). Size, temperature, and fitness: Three rules. Evolutionary Ecology Research, 10(2), 251-268.

Kirk Green, C., Moore, P. J., \& Sial, A. A. (2019). Impact of heat stress on development and fertility of Drosophila suzukii Matsumura (Diptera: Drosophilidae). Journal of Insect Physiology, 114, 45-52. https://doi. org/10.1016/j.jinsphys.2019.02.008

Kodric-Brown, A., \& Brown, J. H. (1987). Anisogamy, sexual selection, and the evolution and maintenance of sex. Evolutionary Ecology, 1(2), 95-105. https://doi.org/10.1007/BF02067393 
Lenth, R. (2020). emmeans: Estimated marginal means, aka least-squares means. Retrieved from https://CRAN.R-project.org/package=emmeans

Loisel, A., Isla, A., \& Daufresne, M. (2019). Variation of thermal plasticity in growth and reproduction patterns: Importance of ancestral and developmental temperatures. Journal of Thermal Biology, 84, 460468. https://doi.org/10.1016/j.jtherbio.2019.07.029

Lutterschmidt, W. I., \& Hutchison, V. H. (1997). The critical thermal maximum: History and critique. Canadian Journal of Zoology, 75(10), 1561-1574. https://doi.org/10.1139/z97-783

MacPherson, A., Yun, L., Barrera, T. S., Agrawal, A. F., \& Rundle, H. D. (2018). The effects of male harm vary with female quality and environmental complexity in Drosophila melanogaster. Biology Letters, 14(8), 20180443. https://doi.org/10.1098/rsbl.2018.0443

Manning, J. T. (1984). Males and the advantage of sex. Journal of Theoretical Biology, 108(2), 215-220. https://doi.org/10.1016/ S0022-5193(84)80067-3

Martinossi-Allibert, I., Rueffler, C., Arnqvist, G., \& Berger, D. (2019) The efficacy of good genes sexual selection under environmental change. Proceedings of the Royal Society B: Biological Sciences, 286(1896), 20182313. https://doi.org/10.1098/rspb.2018.2313

Martinossi-Allibert, I., Thilliez, E., Arnqvist, G., \& Berger, D. (2019). Sexual selection, environmental robustness, and evolutionary demography of maladapted populations: A test using experimental evolution in seed beetles. Evolutionary Applications, 12(7), 13711384. https://doi.org/10.1111/eva.12758

McNamara, K. B., van Lieshout, E., \& Simmons, L. W. (2014). A test of the sexy-sperm and good-sperm hypotheses for the evolution of polyandry. Behavioral Ecology, 25(4), 989-995. https://doi.org/10.1093/ beheco/aru067

Mironidis, G. K., \& Savopoulou-Soultani, M. (2010). Effects of heat shock on survival and reproduction of Helicoverpa armigera (Lepidoptera: Noctuidae) adults. Journal of Thermal Biology, 35(2), 59-69. https:// doi.org/10.1016/j.jtherbio.2009.11.001

Nguyen, T. M., Bressac, C., \& Chevrier, C. (2013). Heat stress affects male reproduction in a parasitoid wasp. Journal of Insect Physiology, 59(3), 248-254. https://doi.org/10.1016/j.jinsphys.2012.12.001

Oku, K., Price, T. A. R., \& Wedell, N. (2019). Does mating negatively affect female immune defences in insects? Animal Biology, 69(1), 117-136. https://doi.org/10.1163/15707563-20191082

Parker, G. A. (2006). Sexual conflict over mating and fertilization: An overview. Philosophical Transactions of the Royal Society B: Biological Sciences, 361(1466), 235-259. https://doi.org/10.1098/ rstb.2005.1785

Parratt, S. R., Walsh, B. S., Metelmann, S., White, N., Manser, A., Bretman, A. J., Hoffmann, A. A., Snook, R. R., \& Price, T. A. R. (2021). Temperatures that sterilize males better match global species distributions than lethal temperatures. Nature Climate Change, 11(6), 481-484. https://doi.org/10.1038/s41558-021-01047-0

Parrett, J. M., \& Knell, R. J. (2018). The effect of sexual selection on adaptation and extinction under increasing temperatures. Proceedings of the Royal Society B: Biological Sciences, 285(1877), 20180303. https://doi.org/10.1098/rspb.2018.0303

Pilakouta, N., \& Ålund, M. (2021). Sexual selection and environmental change: What do we know and what comes next? Current Zoology, zoab021. https://doi.org/10.1093/cz/zoab021

Plesnar-Bielak, A., Skrzynecka, A. M., Prokop, Z. M., \& Radwan, J. (2012) Mating system affects population performance and extinction risk under environmental challenge. Proceedings of the Royal Society B: Biological Sciences, 279(1747), 4661-4667. https://doi.org/10.1098/ rspb.2012.1867

Porcelli, D., Gaston, K. J., Butlin, R. K., \& Snook, R. R. (2017). Local adaptation of reproductive performance during thermal stress. Journa of Evolutionary Biology, 30(2), 422-429. https://doi.org/10.1111/ jeb.13018
R Core Team. (2020). R: A language and environment for statistical computing. R Foundation for Statistical Computing. Retrieved from https:// www.R-project.org/

Rankin, D. J., Dieckmann, U., \& Kokko, H. (2011). Sexual conflict and the tragedy of the commons. The American Naturalist, 177(6), 780-791. https://doi.org/10.1086/659947

Reinhardt, K., Naylor, R. A., \& Siva-Jothy, M. T. (2009). Ejaculate components delay reproductive senescence while elevating female reproductive rate in an insect. Proceedings of the National Academy of Sciences of the United States of America, 106(51), 21743-21747. https://doi.org/10.1073/pnas.0905347106

Rönn, J. L., \& Hotzy, C. (2012). Do longer genital spines in male seed beetles function as better anchors during mating? Animal Behaviour, 83(1), 75-79. https://doi.org/10.1016/j.anbehav.2011.10.007

Rönn, J. L., Katvala, M., \& Arnqvist, G. (2006). The costs of mating and egg production in Callosobruchus seed beetles. Animal Behaviour, 72(2), 335-342. https://doi.org/10.1016/j.anbehav.2005.10.024

Rönn, J. L., Katvala, M., \& Arnqvist, G. (2007). Coevolution between harmful male genitalia and female resistance in seed beetles. Proceedings of the National Academy of Sciences of the United States of America, 104(26), 10921-10925. https://doi.org/10.1073/pnas.0701170104

Rönn, J. L., Katvala, M., \& Arnqvist, G. (2008). Interspecific variation in ejaculate allocation and associated effects on female fitness in seed beetles. Journal of Evolutionary Biology, 21(2), 461-470. https://doi. org/10.1111/j.1420-9101.2007.01493.x

Rowe, L., \& Houle, D. (1996). The lek paradox and the capture of genetic variance by condition dependent traits. Proceedings of the Royal Society of London. Series B: Biological Sciences, 263(1375), 14151421. https://doi.org/10.1098/rspb.1996.0207

Sales, K., Vasudeva, R., Dickinson, M. E., Godwin, J. L., Lumley, A. J., Michalczyk, Ł., Hebberecht, L., Thomas, P., Franco, A., \& Gage, M. J. G. (2018). Experimental heatwaves compromise sperm function and cause transgenerational damage in a model insect. Nature Communications, 9(1), 4771. https://doi.org/10.1038/s41467-01807273-z

Sales, K., Vasudeva, R., \& Gage, M. J. G. (2021). Fertility and mortality impacts of thermal stress from experimental heatwaves on different life stages and their recovery in a model insect. Royal Society Open Science, 8(3), 201717. https://doi.org/10.1098/rsos.201717

Savalli, U. M., \& Fox, C. W. (1999). The effect of male mating history on paternal investment, fecundity and female remating in the seed beetle Callosobruchus maculatus. Functional Ecology, 13(2), 169-177. https://doi.org/10.1046/j.1365-2435.1999.00287.x

Schärer, L., Rowe, L., \& Arnqvist, G. (2012). Anisogamy, chance and the evolution of sex roles. Trends in Ecology \& Evolution, 27(5), 260-264. https://doi.org/10.1016/j.tree.2011.12.006

Schou, M. F., Bonato, M., Engelbrecht, A., Brand, Z., Svensson, E. I., Melgar, J., Muvhali, P. T., Cloete, S. W. P., \& Cornwallis, C. K. (2021). Extreme temperatures compromise male and female fertility in a large desert bird. Nature Communications, 12(1), 666. https://doi. org/10.1038/s41467-021-20937-7

Silva, W. T. A. F., Sáez-Espinosa, P., Torijo-Boix, S., Romero, A., Devaux, C., Durieux, M., Gómez-Torres, M. J., \& Immler, S. (2019). The effects of male social environment on sperm phenotype and genome integrity. Journal of Evolutionary Biology, 32(6), 535-544. https:// doi.org/10.1111/jeb.13435

Svensson, E. I., \& Connallon, T. (2019). How frequency-dependent selection affects population fitness, maladaptation and evolutionary rescue. Evolutionary Applications, 12(7), 1243-1258. https://doi. org/10.1111/eva.12714

Svensson, E. I., Gómez-Llano, M., \& Waller, J. T. (2020). Selection on phenotypic plasticity favors thermal canalization. Proceedings of the National Academy of Sciences of the United States of America, 117(47), 29767-29774. https://doi.org/10.1073/pnas.2012454117 
Terblanche, J. S., Deere, J. A., Clusella-Trullas, S., Janion, C., \& Chown, S. L. (2007). Critical thermal limits depend on methodological context. Proceedings of the Royal Society B: Biological Sciences, 274(1628), 2935-2943. https://doi.org/10.1098/ rspb. 2007.0985

Tomkins, J. L., Radwan, J., Kotiaho, J. S., \& Tregenza, T. (2004). Genic capture and resolving the lek paradox. Trends in Ecology \& Evolution, 19(6), 323-328. https://doi.org/10.1016/j.tree.2004.03.029

van Heerwaarden, B., \& Sgrò, C. M. (2021). Male fertility thermal limits predict vulnerability to climate warming. Nature Communications, 12(1), 2214. https://doi.org/10.1038/s41467-021-22546-w

Varela, R., Rodríguez-Díaz, L., \& deCastro, M. (2020). Persistent heat waves projected for Middle East and North Africa by the end of the 21st century. PLoS One, 15(11), e0242477. https://doi.org/10.1371/ journal.pone. 0242477

Vasudeva, R., Deeming, D. C., \& Eady, P. E. (2014). Developmental temperature affects the expression of ejaculatory traits and the outcome of sperm competition in Callosobruchus maculatus. Journal of Evolutionary Biology, 27(9), 1811-1818. https://doi.org/10.1111/ jeb.12431

Vasudeva, R., Deeming, D. C., \& Eady, P. E. (2021). Age-specific sensitivity of sperm length and testes size to developmental temperature in the bruchid beetle. Journal of Zoology, 314(4), 285-295. https:// doi.org/10.1111/jzo.12884

Walsh, B. S., Parratt, S. R., Hoffmann, A. A., Atkinson, D., Snook, R. R., Bretman, A., \& Price, T. A. R. (2019). The impact of climate change on fertility. Trends in Ecology \& Evolution, 34(3), 249-259. https://doi. org/10.1016/j.tree.2018.12.002

Walters, R. J., Blanckenhorn, W. U., \& Berger, D. (2012). Forecasting extinction risk of ectotherms under climate warming: An evolutionary perspective. Functional Ecology, 26(6), 1324-1338. https://doi. org/10.1111/j.1365-2435.2012.02045.x

Whitlock, M. C., \& Agrawal, A. F. (2009). Purging the genome with sexual selection: Reducing mutation load through selection on males. Evolution, 63(3), 569-582. https://doi.org/10.1111/j.1558-5646.2008.00558.x

Wickham, H. (2016). ggplot2: Elegant graphics for data analysis. SpringerVerlag. Retrieved from https://ggplot2.tidyverse.org

Yamane, T., Goenaga, J., Rönn, J. L., \& Arnqvist, G. (2015). Male seminal fluid substances affect sperm competition success and female reproductive behavior in a seed beetle. PLoS One, 10(4), e0123770. https://doi.org/10.1371/journal.pone.0123770

Yun, L., Chen, P. J., Singh, A., Agrawal, A. F., \& Rundle, H. D. (2017). The physical environment mediates male harm and its effect on selection in females. Proceedings of the Royal Society B: Biological Sciences, 284(1858), 20170424. https://doi.org/10.1098/rspb.2017.0424

\section{SUPPORTING INFORMATION}

Additional supporting information may be found in the online version of the article at the publisher's website.

How to cite this article: Baur, J., Jagusch, D., Michalak, P., Koppik, M., \& Berger, D. (2022). The mating system affects the temperature sensitivity of male and female fertility. Functional Ecology, 36, 92-106. https://doi.org/10.1111/1365-2435.13952 